\title{
A AVALIAÇÃO DA APRENDIZAGEM DOS EDUCANDOS QUE PERMANECEM EM TEMPO INTEGRAL NO MUNICÍPIO DE ANGRA DOS REIS/RJ POR MEIO DO PROGRAMA NOVO MAIS EDUCAÇÃO: DISCUSSÕES PRELIMINARES SOBRE O PAPEL DA EDUCAÇÃO NA CONSTRUÇÃO DO CONHECIMENTO
}

\author{
LA EVALUACIÓN DEL APRENDIZAJE DE LOS EDUCANDOS QUE PERMANECEN \\ EN TIEMPO INTEGRAL EN EL MUNICIPIO DE ANGRA DOS REIS/RJ POR MEDIO \\ DEL PROGRAMA NUEVO MÁS EDUCACIÓN: DISCUSIONES PRELIMINARES \\ SOBRE EL PAPEL DE LA EDUCACIÓN EN LA CONSTRUCCIÓN DEL \\ CONOCIMIENTO
}

\author{
THE EVALUATION OF THE LEARNING OF EDUCATIONAL TEAMS THAT \\ REMAIN IN COMPREHENSIVE TIME IN THE MUNICIPALITY OF ANGRA DOS \\ REIS / RJ THROUGH THE NEW PROGRAM MORE EDUCATION: PRELIMINARY \\ DISCUSSIONS ON THE ROLE OF EDUCATION IN THE CONSTRUCTION OF \\ KNOWLEDGE
}

\author{
Marcio Bernardino SIRINO ${ }^{1}$ \\ Patrícia Flavia MOTA ${ }^{2}$
}

\begin{abstract}
RESUMO: A partir da inserção do Programa Novo Mais Educação na Rede Municipal de Ensino de Angra dos Reis/ RJ e sua orientação para aplicação de avaliações padronizadas aos estudantes que permanecem em tempo integral para medir a aprendizagem em língua portuguesa e matemática, este presente artigo foi elaborado objetivando, por meio da pesquisa bibliográfica sobre as temáticas que se evidenciam nesta produção apresentar as reflexões iniciais realizadas sobre o papel da educação na construção do conhecimento.
\end{abstract}

PALAVRAS-CHAVE: Educação integral. Educação em tempo integral. Avaliação. Papel da educação.

RESUMEN: A partir de la inserción del Programa Nuevo Más Educación en la Red Municipal de Enseñanza de Angra dos Reis/RJ y su orientación para la aplicación de evaluaciones estandarizadas a los estudiantes que permanecen a tiempo completo para medir el aprendizaje en lengua portuguesa y matemática, este presente artículo fue elaborado

\footnotetext{
1 Prefeitura Municipal de Angra dos Reis (PMAR), Angra dos Reis - RJ - Brasil. Mestre em Educação (PPGEdu/UNIRIO); Especialista em Alfabetização dos Estudantes das Classes Populares (UFF/Angra dos Reis); Pedagogo (UCB); Servidor Público da Prefeitura Municipal de Angra dos Reis (PMAR); Membro do Núcleo de Estudos - Tempos, Espaços e Educação Integral (NEEPHI/UNIRIO); Pesquisador Integrante do Grupo de Estudos, Pesquisas e Extensão Fora da Sala de Aula: Formações, Representações e Práticas educativas não escolares e/ou extracurriculares no município de São Gonçalo (UERJ-FFP/São Gonçalo). ORCID: <http://orcid.org/0000-0001-5874-6225>. E-mail: pedagogomarcio@gmail.com

${ }^{2}$ Universidade do Estado do Rio de Janeiro (UERJ), Rio de Janeiro - RJ - Brasil. Professora do Ensino Fundamental da Prefeitura Municipal de Duque de Caxias; Integrante do Núcleo de Estudos - Tempos, Espaços e Educação Integral (NEEPHI - UNIRIO). Pesquisadora do Grupo de Estudos, Pesquisa e Extensão Fora da Sala de Aula: formações, representações e práticas educativas não escolares. (UERJ-FFP/ São Gonçalo). DOI: <http://orcid.org/0000-0001-9471-2137>. E-mail: patriciamotauerjffp@ hotmail.com
} 
objetivando, por medio de la investigación bibliográfica sobre las temáticas que se evidencian en esta producción presentar las reflexiones iniciales realizadas sobre el papel de la educación en la construcción del conocimiento.

PALABRAS CLAVE: Educación integral. Educación a tiempo completo. Evaluación. Papel de la educación.

ABSTRACT: From the insertion of the New More Education Program in the Municipal School Network of Angra dos Reis/RJ and its orientation for the application of standardized assessments to students who remain full time to measure learning in portuguese and mathematics, this article was elaborated aiming, through the bibliographic research on the themes that are evidenced in this production, present the initial reflections about the role of education in the construction of knowledge.

KEYWORDS: Integral education. Full-time. Evaluation. Role of education.

\section{Uma contextualização relevante}

Faz-se necessário apresentar uma pequena contextualização que elucide ao leitor os motivos pelos quais este texto foi elaborado e localizado, em suas problematizações iniciais, no município de Angra dos Reis/RJ.

Há cerca de quase 10 (dez) anos atuo como servidor público da Prefeitura Municipal de Angra dos Reis (PMAR). Trabalhando, atualmente, num Centro de Educação em Tempo Integral (CETI) fui me percebendo um "educador integral" e ampliando minha formação pedagógica.

Tive a oportunidade de atuar na coordenação das escolas de educação em tempo integral de Angra dos Reis e, em seguida, ampliar minha discussão sobre a temática da Educação Integral e(m) Tempo Integral no Mestrado em Educação para o Programa de PósGraduação da Universidade Federal do Estado do Rio de Janeiro (PPGEdu/UNIRIO) e pesquisar a "Trajetória da Educação em Tempo Integral na Rede Municipal de Ensino de Angra dos Reis (RJ): uma composição entre o universal e o focal?", sob orientação da Prof. ${ }^{\text {a }}$ Dr ${ }^{\mathrm{a}}$. Lígia Martha Coimbra da Costa Coelho.

Em 2017, após defesa da dissertação, retorno à Rede Municipal de Angra dos Reis e, infelizmente, contemplo o desmantelamento da Política Municipal de Educação em Tempo Integral, além de uma realidade escolar muito sucateada e a inserção do Programa Novo Mais Educação (PNME) - que trouxe uma nova lógica à ampliação da jornada escolar dos alunos e, também, um foco no desenvolvimento da Língua Portuguesa e da Matemática - o que possibilita-nos identificar uma perspectiva de veiculação do trabalho pedagógico

RPGE- Revista on line de Política e Gestão Educacional, Araraquara, v.22, n.1, p. 381-394, jan./abr. $2018 \quad$ ISSN: 1519-9029 DOI: $10.22633 /$ rpge.v22.n.1.2018.10710 
desenvolvido pelo referido Programa às avaliações externas, padronizadas e muito associadas à "Provinha Brasil” - por conta desta 'focalização' nestas duas áreas do conhecimento.

Convém salientar que, ao entrar no Sistema Integrado de Monitoramento, Execução e Controle (SIMEC), plataforma do PDDE-Interativo ${ }^{3}$, no qual se instala o PNME, para efetuar o preenchimento dos dados solicitados (cadastro de alunos, cadastro de mediadores de aprendizagem, cadastro de facilitadores, enturmação dos alunos, dentre outros) foi possível perceber diversos modelos de provas para serem aplicadas aos estudantes e lançadas as suas devidas marcações num dado tempo limite - o que me motivou a dar continuidade produzindo reflexões dentro da temática da Educação Integral e(m) Tempo Integral, porém com um olhar voltado para a discussão sobre a avaliação da aprendizagem dos educandos e sua relação com o papel da educação na construção de conhecimento.

\section{Introdução}

"Angra dos Reis e Ipanema. Iracema e Itamaracá. Porto Seguro, São Vicente. Braços abertos sempre a esperar..."

(Lulu Santos)

A epígrafe que dispomos no início desta introdução - fragmento da música "Descobridor dos Sete Mares", de Lulu Santos - nos possibilita afirmar que há uma multiplicidade de contextos sociais que - muito embora estejam todos inseridos no solo brasileiro - possuem suas especificidades e características peculiares.

Neste sentido, de antemão questionamos como avaliar a aprendizagem dos educandos, de norte a sul deste país, da mesma forma - tendo a clareza de que cada território se configura numa luta política acerca do que é educação, do papel social da escola, do processo de construção de conhecimento, ensino-aprendizagem e, neste bojo, de avaliação?

Avaliamos para nivelar ou para modificar a prática pedagógica, tendo como foco a aprendizagem do educando e o seu desenvolvimento humano mais completo?

Segundo Hoffman (2005),

A avaliação é reflexão transformada em ação. Ação, essa que nos impulsiona a novas reflexões. Reflexão permanente do educador sobre sua realidade, e acompanhamento de todos os passos do educando na sua trajetória de

${ }^{3}$ Segundo o Portal do MEC, o PDDE-Interativo é a "ferramenta de planejamento da gestão escolar disponível para todas as escolas públicas. Ele foi desenvolvido pelo Ministério da Educação em parceria com as secretarias estaduais e municipais e sua principal características é a natureza autoinstrucional e interativa de cada tela". Disponível em: <http://pdeescola.mec.gov.br/index.php/pde-interativo〉. Acesso em: 09 ago. 2017. 
construção de conhecimento. Um processo interativo, através do qual educandos e educadores aprendem sobre si mesmos e sobre a realidade escolar no ato próprio da avaliação (HOFFMAN, 2005, p. 17).

Em tempos de cortes na área da educação, do estabelecimento de um 'teto' para os investimentos neste campo, intensificação da crise política e infindos retrocessos em todos os segmentos da sociedade, entendemos a existência das avaliações de larga escala na perspectiva de se estabelecer relações com outros países, angariar investimentos para o Brasil e, ainda, abrir as fronteiras do conhecimento com a própria articulação com os organismos internacionais.

No entanto, o que estas avaliações 'medem'? Quais os pressupostos que a elas subjazem? Em quais concepções se sustentam? - Questões estas, dentre tantas outras, que nos possibilita delimitar nossa problemática neste texto, a saber: a avaliação da aprendizagem dos educandos que permanecem em tempo integral por meio do Programa Novo Mais Educação e sua relação com o papel da educação na construção do conhecimento.

Com um sistema nacional de avaliação que vem se tornando maior e mais complexo, no qual os resultados das avaliações geram consequências imediatas para indivíduos, escolas e sistemas de ensino, é importante que cada iniciativa de avaliação seja coerente, articulada e tecnicamente fundamentada e apresenta de forma mais clara e transparente o porquê, para que, para quem, o que e como avaliar. (PESTANA, 2016, p. 81)

Neste contexto, convém salientar que no ano de 2007 foi criado o Programa Mais Educação (PME) por meio da portaria interministerial n.17/2007; porém, ao longo dos anos, muitos estudos vieram apontando as fragilidades que o referido programa apresentava enquanto uma "estratégia do Ministério da Educação para induzir a ampliação da jornada escolar e a organização curricular na perspectiva da Educação Integral” (BRASIL, 2007), feito este que, no bojo da crise econômica, culminou, no ano de 2015, com o congelamento de diversas políticas sociais e educacionais - dentre elas, o PME - e, a partir de uma avaliação apresentada pelo atual Ministro da Educação e Cultura, Mendonça Filho, o referido programa permaneceu congelado, sem repasse de verbas às Unidades Escolares e, em contrapartida, foi criado o Programa Novo Mais Educação (PNME), pela Portaria 1.144/2016, com o objetivo de "melhorar a aprendizagem em língua portuguesa e matemática no ensino fundamental" (BRASIL, 2016).

Convém destacar que este ordenamento normativo não sinaliza o término do PME, entretanto, podemos inferir esta construção frente aos desdobramentos da política e da materialização do próprio PNME no cotidiano das escolas públicas. Sendo assim, faz se 
necessário apresentar o foco deste 'novo’ programa e sua vinculação com os indicadores de aprendizagem que nos faz repensar em qual concepção de educação integral o programa articula a ampliação do tempo para o estudante e, ainda, qual o papel da educação neste processo formativo.

Sirino (2017), em pesquisa sobre a "Trajetória da Educação em Tempo Integral na Rede Municipal de Ensino de Angra dos Reis (RJ)", identificou que, nesta cidade, duas políticas, a partir de 2009, foram desenvolvidas, a saber:

- Política Municipal denominada Centro de Educação e Horário Integral (CEHI), que implantada em 4 (quatro) Unidades Escolares, ofertava aos educandos a ampliação da jornada escolar.

- Política Federal através do Programa Mais Educação, incluído a partir de 2010, em cerca de 28 (vinte e oito) escolas da Rede Municipal de Ensino.

Um dos achados dessa pesquisa - que foi construída com base na discussão sobre a universalidade versus focalização na implantação das políticas públicas - foi perceber que a política municipal (CEHIs), que tinha um viés universal se 'focalizou' e a política federal que tinha uma perspectiva focal (PME), se 'universalizou' nesse município.

A partir desse estudo - que analisou a trajetória dessas duas políticas - e, ainda, levando em consideração o momento histórico atual de finalização do PME, o sucateamento da política municipal de educação em tempo integral de Angra dos Reis e, ainda, a inserção do Programa Novo Mais Educação com foco em Língua Portuguesa e Matemática propõe-se, neste texto, com o objetivo geral, ampliar a discussão sobre o impacto do Programa Novo Mais Educação (PNME) na aprendizagem dos educandos que permanecem em tempo integral na Rede Municipal de Ensino de Angra dos Reis/RJ bem como tecer considerações primárias sobre o papel da educação nesta contemporaneidade.

Convém salientar que, atualmente, a política municipal de Educação em Tempo Integral, criada pela resolução SECT n. 005/2009 e reelaborada pela resolução SECT n.003/2016, encontra-se totalmente reconfigurada, por conta da necessidade de cortes na área da Educação e a inserção do PNME nos 4 (quatro) Centros de Educação em Tempo Integral (CETIs) e em 27 (vinte e sete) escolas da Rede Municipal de Ensino de Angra dos Reis.

Podemos destacar que, das 75 (setenta e cinco) escolas mantidas pelo poder público municipal, 31 (trinta e uma) fizeram adesão ao PNME - configurando-se, assim, neste momento sócio-histórico-político, a única proposta de ampliação da jornada escolar de 
[alguns] educandos para uma educação em tempo integral ${ }^{4}$. Sinalizamos o pronome 'alguns' por que, nessas escolas, nem todos os alunos são contemplados pelo PNME.

Sendo assim, frente a contextualização exposta, elaboramos este artigo que se baseia, metodologicamente, na pesquisa bibliográfica da temática da Educação Integral (em) Tempo Integral e da Avaliação de forma a estabelecer considerações sobre o papel da educação nesta conjuntura.

Especificamente sobre as duas grandes temáticas que se evidenciam nesta pesquisa, sinalizamos, na sequência, os autores selecionados que embasam nossa discussão teórica e conceitual.

Sobre o campo da Educação Integral e(m) Tempo Integral, nos alicerçamos nas contribuições de Coelho (2009); Cavaliere (2009); Maurício (2009) - na perspectiva de potencializar a importância da ampliação da jornada escolar para os educandos e sua relação com a promoção de novas oportunidades de aprendizagem.

Por sua vez, com relação à discussão sobre Avaliação, nos fundamentamos em autores consagrados que, historicamente, vêm contribuindo para a potencialização desta problematização no cenário educacional, a saber: Hoffman (2005); Freitas (2016) e Fernandes (2014), dentre outros.

Neste bojo, convém evidenciar que esta produção se justifica pela sua possibilidade de trazer à reflexão uma política recém-criada, ampliar as discussões no campo das avaliações (externas, padronizadas, formatadas e, por vezes, descontextualizadas), abrir canais de problematização acerca do papel da Educação nesta contemporaneidade e, ainda, questionar a função social da escola.

Perspectivas estas que apresentamos nas seções que se seguem a fim de potencializar a nossa discussão.

\section{Educação Integral e(m) Tempo Integral}

O poeta Mário Quintana, em sua poesia “O tempo", nos insta a perceber que enquanto o tempo cronológico, advindo de Chronos (ou Cronos) - marcado pela quantidade e pelo controle das horas - está passando/acabando, junto a ele também se esvai o tempo da experiência, da vivência e da subjetividade - que prima pela oportunidade de qualificar o

${ }^{4}$ Com relação à educação em tempo integral, evidenciamos que a legislação brasileira considera como sendo a oferta de educação "igual ou superior a 7 (sete) horas diárias durante todo o ano letivo" (BRASIL, 2014, Meta 6, Estratégia 6.1).

RPGE- Revista on line de Política e Gestão Educacional, Araraquara, v.22, n.1, p. 381-394, jan./abr. 2018 
tempo do presente - Kairós, assim o chamamos, como podemos identificar no fragmento que segue esta relação entre os diferentes tempos.

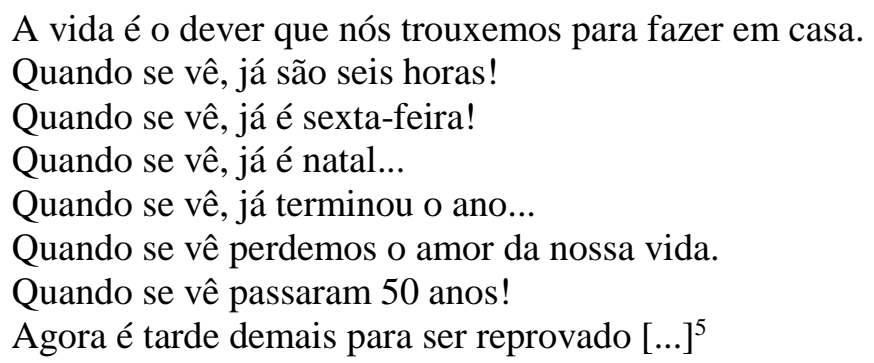

Este trecho nos possibilita percebemos o quanto estamos envolvidos pelo tempo cronológico, com a padronização das tarefas, organização e encadeamento sequencial dos fatos sem, diretamente, os relacionarmos com a possibilidade do devir (transformação), presente na experiência.

O tempo - tanto cronológico quanto da experiência - está associado a uma construção socioistórica e cultural (PARENTE, 2010) e essa forma de o percebermos atualmente na sociedade - nas diversas instituições, nas escolas, nas relações e nas ações que envidamos ou somos acometidos - sempre se pauta na correria dos dias, no passar dos tempos e na escassez de vida que produza novos sentidos e que estes caracterizem nossas escolhas.

Vivemos tempos líquidos, como nos afirma Bauman, em que as horas demarcadas pelos relógios nos controlam sobremaneira e a constante mudança no ritmo da sociedade direciona nossas escolhas, fragilizando, assim, as nossas ações. Tempos em que um dia passa num piscar de olhos e a sensação de que o mesmo não foi aproveitado nem otimizado de maneira adequada, oportuna e produtiva, sempre nos entorpece, ou seja, o tempo Chronos atropela o tempo Kairós, nos imobilizando de toda e qualquer possibilidade de transformação.

Controlados pelas pressões da sociedade para nos inserirmos nesta lógica de permanentes mudanças e de constantes exigências, de adequações e de reformulações a novos tempos, trazemos, no bojo deste oxímoro, nossa compreensão sobre o tempo enquanto produto da criação humana, que tem passado por diversas transformações ao longo dos tempos, inclusive, na escola pública - lócus de nossa discussão, como nos aponta Parente (2010):

O tempo da escola é influenciado pelo tempo sociohistórico: a rítmica de determinado contexto social, cultural e histórico determina as cadências e os ritmos impressos na dinâmica das instituições sociais e dos próprios sujeitos

5 26/11/2017. Poema “O tempo" disponível em: <http://pensador.uol.com.br/frase/MTc0MDg/> 
que fazem parte dessas instituições em cada contexto histórico (PARENTE, 2010, p. 142).

Trazemos este excerto para pensarmos o quanto os diferentes tempos influenciam no cotidiano escolar, de forma a intervir no desenvolvimento da multidimensionalidade do educando - um olhar que contemple todas as suas diferentes dimensões formadoras ${ }^{6}$.

Atualmente, passamos de uma perspectiva de tempo escolar fragmentado, contabilizado, recortado e que, historicamente, se relacionava com a nossa percepção limitada sobre o processo de construção de conhecimentos e de legitimação do próprio saber socializado e produzido na comunidade escolar para uma nova compreensão do tempo - um tempo que modifica a lógica da organização hierárquica para uma proposta mais dialógica e horizontalizada, que insere novos valores e humaniza as relações inseridas no cotidiano escolar e que, para além da instrução, preocupa-se com o desenvolvimento de uma educação integral, ou seja, que busque promover uma formação humana mais completa para os alunos (COELHO, 2009).

Pensar sobre os diferentes tempos produzidos no/para o cotidiano escolar nos leva a refletir sobre o início da escolarização obrigatória dos educandos bem como a sua trajetória.

Parente (2008) faz um levantamento das legislações que abordam o tempo de início e do percurso no processo de escolarização dos alunos, acrescentando um olhar sobre as políticas públicas implantadas na educação na perspectiva de refletir se as mesmas contemplam ou não os sujeitos do processo.

Essas políticas consideram os múltiplos atores inseridos no cotidiano escolar? Suas necessidades? Seus diferentes tempos? Constituem-se, efetivamente, enquanto "políticavida"?

Frente a estes questionamentos, sinalizamos que, atualmente, a legislação brasileira aponta para "a educação básica obrigatória e gratuita dos 4 (quatro) aos 17 (dezessete) anos" (BRASIL, 2013) e, neste bojo, acrescentamos, ainda, a perspectiva para o "atendimento à criança de, no mínimo, 4 (quatro) horas diárias para o turno parcial e de 7 (sete) horas para jornada integral" (BRASIL, 2013).

Neste sentido, enquanto pressuposto legal específico sobre a educação em tempo integral, encontramos, no atual Plano Nacional de Educação (PNE 2014-2024), a orientação

${ }^{6}$ No que se refere às diferentes dimensões formadoras do sujeito, Guará (2006) relata que “A integralidade da pessoa humana abarca a intersecção dos aspectos biológico-corporais, do movimento humano, da sociabilidade, da cognição, do afeto, da moralidade, em um contexto tempo-espacial" (p. 16).

RPGE- Revista on line de Política e Gestão Educacional, Araraquara, v.22, n.1, p. 381-394, jan./abr. 2018 ISSN: 1519-9029 
A avaliação da aprendizagem dos educandos que permanecem em tempo integral no município de Angra dos Reis/RJ por meio do

Programa Novo Mais Educação: discussões preliminares sobre o papel da educação na construção do conhecimento

para a oferta de educação "igual ou superior a 7 (sete) horas diárias durante todo o ano letivo" (BRASIL, 2014, Meta 6, Estratégia 6.1).

Essa normatização nos provoca inúmeras inquietações sobre o tempo escolar do aluno, levando em consideração variados fatores que influenciam no seu processo de formação, como nos faz refletir Arroyo (2004), de maneira poética e consistente:

Em cada aluno há uma história pessoal, grupal, de gênero, raça, classe ou idade. Percursos singulares e coletivos que se entrelaçam com seus percursos escolares. É impossível pretender entender este isolado daqueles (ARROYO, 2004, p. 64).

Acreditamos que o tempo escolar regular, composto pelas 4 (quatro) horas mínimas, é insuficiente para as variadas demandas que a escola pública possui na atualidade no que se refere à apropriação/socialização dos conhecimentos, historicamente construídos, e na oferta aos alunos de vivências significativas - que promovam o seu desenvolvimento humano mais completo, ao percebê-lo integralmente - em suas diferentes dimensões formadoras.

$\mathrm{Na}$ busca por legitimar os diferentes tempos do aluno, reconhecemos o valor da ampliação de seu percurso escolar, bem como de sua jornada diária para uma educação em tempo integral, destacando que o aumento do tempo de obrigação da educação básica pode promover maiores oportunidades de aprendizagem aos alunos, bem como a ampliação da jornada escolar diária do educando, uma vez que esta tem condições de favorecer que as múltiplas aprendizagens dialoguem com a realidade social do aluno, promova uma organização curricular de maneira articulada e integrada e, ainda, venha a objetivar a emancipação desses que se constituem sujeitos do processo educativo.

Discutimos sobre a educação em tempo integral por reconhecermos a dívida histórica que socialmente possuímos com os alunos das classes populares (MAURÍCIO, 2009) e por termos consciência de que cada educando aprende de uma maneira diferente e num 'espaçotempo' próprio, que não pode ser imposto pelo tempo cronológico, mas sim valorizado em todo o processo de ensino-aprendizagem.

Neste sentido, para garantir que este olhar mais ampliado seja instaurado, nos direcionamos a repensar sobre como esse tempo será otimizado no cotidiano escolar para que não seja ofertado aos alunos "mais da mesma coisa", como apontava Paro (2009), e que, efetivamente, eles recebam uma educação que integre diferentes áreas do conhecimento, desperte inúmeros sentidos e promova o seu desenvolvimento pleno - em sua integralidade.

Neste caminhar, abre-nos a necessidade de repensar, inclusive, o ato de avaliar os alunos nas escolas de educação em tempo integral, pois, se o educando passar cerca de 7 
(sete) horas num mesmo espaço que, em tese, prima pela sua formação integral, como avaliar de maneira tão padronizada e (des)igual?

Questões que ampliamos na próxima seção.

\section{Avaliação para potencializar a aprendizagem ou para nivelar dificuldades?}

A discussão sobre a temática da Avaliação, há muitos anos, vem sendo promovida no cenário educacional e não se configura 'novidade' no sentido que diversos autores e pesquisadores vêm produzindo reflexões acerca do ato de avaliar, das avaliações externas e da política de avaliação que as sustentam. No entanto, muito embora tenhamos avançado nas questões teóricas e conceituais, ainda é muito presente, nas diferentes localidades, do solo brasileiro, encontrarmos a prática da avaliação padronizada e descontextualizada.

A partir das contribuições de Alavarse et al. (2013), encontramos as justificativas das avaliações externas, atreladas ao monitoramento das redes de ensino, como podemos observar no fragmento que se segue:

As experiências iniciais de avaliações externas, até mesmo fora do Brasil, foram justificadas como necessárias para se poder monitorar o funcionamento de redes de ensino e fornecer aos seus gestores subsídios para a formulação de políticas educacionais com focos mais bem definidos em termos dos resultados que, por sua vez, decorreriam das aprendizagens dos alunos (ALAVARSE et al, 2013, p.17).

O que nos causa espécie é identificarmos nas escolas de educação em tempo integral em grande maioria, atreladas a uma concepção de educação que favoreça ao desenvolvimento mais completo dos educandos - essa prática avaliativa que, infelizmente, ao invés de potencializar a aprendizagem, a nosso ver, nivela as dificuldades dos educandos. E, assim, rompe-se com toda a perspectiva de uma educação mais 'integral'.

Como já apresentamos, no início deste artigo, a avaliação da aprendizagem não é um ato de medição, mas sim de reflexão sobre a prática educativa desenvolvida no cotidiano escolar na perspectiva de que se produza um movimento de adequação às necessidades dos alunos a fim de que os mesmos tenham a possibilidade de aprender.

O sentido fundamental da ação avaliativa é o movimento, a transformação. Os pesquisadores muitas vezes se satisfazem com a descoberta do mundo, mas a tarefa do avaliador é a arte de torná-lo melhor. (HOFFMAN, 2005, p. 90) 
A avaliação da aprendizagem dos educandos que permanecem em tempo integral no município de Angra dos Reis/RJ por meio do

Programa Novo Mais Educação: discussões preliminares sobre o papel da educação na construção do conhecimento

Mas, não é essa a perspectiva que viemos observando nas escolas públicas de educação básica. Nas décadas de 80 e 90, o sistema de avaliação externa começou a ser implantado no Brasil com a perspectiva de que, por meio da descentralização, do governo, houvesse maior redemocratização da própria educação.

No entanto, essas avaliações externas trazem, em seu bojo, a perspectiva de ranqueamento dos profissionais e estigmatização das próprias escolas, além de diversas problematizações sobre sua validade e eficiência, como podemos observar nas contribuições de Horta Neto e Junqueira (2016).

Atualmente, as informações produzidas pelo Saeb são objeto de disputas e controvérsias. De um lado, podem ser utilizadas para o diagnóstico, o planejamento, a intervenção e o monitoramento da educação escolar, a fim de melhorar o ensino ofertado ao disponibilizar dados relevantes sobre os êxitos e os problemas encontrados nessa atividade. De outro, tais informações podem viabilizar, conforme a perspectiva política e ideológica pela qual são apreendidas, o ranqueamento, a estigmatização e a responsabilização vertical de escolas e de seus profissionais, por exemplo (HORTA NETO; JUNQUEIRA, 2016, p. 16).

Neste contexto, nos preocupa essa veiculação, no Programa Novo Mais Educação, de aplicação de avaliações padronizadas e elaboradas por instituições que estão distantes da realidade social em que os alunos se encontram inseridos, pois esta prática retira das unidades escolares o principal lócus de reflexão sobre a melhoria da educação.

Podemos observar, nas ponderações de Freitas (2016), que "É a escola que deve ser o centro cultural condutor do processo de mobilização pela melhoria da educação, e não a cultura da avaliação externa, das consultorias e dos órgãos de auditoria e avaliação” (p. 33).

Neste contexto, em que as avaliações externas se avolumam no cotidiano escolar, percebemos que esta perspectiva modifica e condiciona a própria prática dos educadores atrelando-as, assim, a um novo papel social da escola e, sobretudo, da educação.

Aspecto este que pontuamos no desfecho desta produção.

\section{Considerações finais}

Por meio das contribuições de Fernandes (2014), podemos afirmar a relação entre a avaliação da aprendizagem com a função social da escola voltada para uma perspectiva quantitativa de conhecimento na medida em que - com um discurso de baixa qualidade da educação - as avaliações externas, impostas à educação básica, vêm produzindo uma certa responsabilização da escola, culpabilização dos professores, adequação da prática pedagógica 
e hierarquização de saberes, dentre outras mazelas atuais que fazem parte do papel da educação na construção de conhecimentos.

Essa postura reflete a estrutura de sociedade desigual que possuímos na qual os indivíduos encontram-se consumistas, individualistas e totalmente capitalistas - produzindo, a cada dia, processos de fragilidade nos laços humanos e distanciamento entre os pares, como identificamos por modernidade líquida (Bauman, 2004).

No entanto, nas escolas de educação em tempo integral, que primam pela formação integral dos seus educandos, faz-se necessário salientar a importância de navegar na contramão desta sociedade líquido-moderna, na perspectiva de contemplar as diferentes dimensões formadoras do sujeito, como inferimos dos aportes de Cavaliere (2009):

\begin{abstract}
A escola, ao propiciar relações humanas diversificadas e diretas, segue na contramão das tendências do século XXI. É um contraponto às novas e poderosas agências de educação, como mídia e a rede mundial de internet, impessoais, e economicamente interessadas. A vivência democrática cotidiana, no sentido da experimentação de relações humanas baseadas em regras justas e no respeito ao próximo e à coletividade, aliada à vivência cultural diversificada, seriam os fundamentos para a construção de uma educação escolar que pudesse ser chamada de educação integral (CAVALIERE, 2009, p. 50).
\end{abstract}

Desse modo, podemos pontuar que o Programa Novo Mais Educação ao trazer para as unidades escolares avaliações externas e padronizadas, além de não avaliarem qualitativamente - a aprendizagem dos alunos, contribui para a construção de uma escola cuja educação produzida seja “(des)integral”.

\title{
REFERÊNCIAS
}

ALAVARSE, Ocimar. et al. Avaliações externas e qualidade na educação básica: articulações e tendências. Est. Aval. Educ., v. 24, n. 54, p. 12-31, jan./abr., 2013.

ANGRA DOS REIS. Resolução Municipal SECT n ${ }^{\circ} 003$ de 25 de agosto de 2016. Dispõe sobre a alteração da Resolução SECT n ${ }^{\circ} 005$ de 16 de julho de 2009, regulamenta o funcionamento das escolas em tempo integral da Rede Municipal de Ensino de Angra dos Reis e dá outras providências. Boletim Oficial do Município de Angra dos Reis, RJ, 02 set. 2016.

ANGRA DOS REIS. Resolução Municipal SECT n ${ }^{\circ} 005$ de 16 de julho de 2009. Dispõe sobre a criação e o funcionamento dos Centros de Educação e Horário Integral de Angra dos Reis.

Boletim Oficial do Município de Angra dos Reis, RJ, 20 ago. 2009.

ARROYO, Miguel. Imagens quebradas: trajetórias e tempos de alunos e mestres. Petrópolis, RJ: Vozes, 2004. 
A avaliação da aprendizagem dos educandos que permanecem em tempo integral no município de Angra dos Reis/RJ por meio do

Programa Novo Mais Educação: discussões preliminares sobre o papel da educação na construção do conhecimento

BAUMAN, Zygmunt. Amor líquido: sobre a fragilidade dos laços humanos. Rio de Janeiro: Zahar, 2004.

BRASIL. Lei 12.796, de 04 de abril de 2013. Altera a Lei no 9.394, de 20 de dezembro de 1996, que estabelece as diretrizes e bases da educação nacional, para dispor sobre a formação dos profissionais da educação e dar outras providências. Diário Oficial da União, Brasília, DF- 05 de abr. 2013.

BRASIL. Lei no 13.005, de 24 de junho de 2014. Aprova o Plano Nacional de Educação. Diário Oficial da União, Brasília, DF, 26 de jun. 2014.

BRASIL. Portaria Interministerial n ${ }^{\circ} .17$, de 24 de abril de 2007. Diário Oficial da União, Brasília, DF, 26 abril. 2007.

BRASIL. Portaria n$^{\circ} 1144$, de 10 de outubro de 2016. Institui o Programa Novo Mais Educação, que visa melhorar a aprendizagem em língua portuguesa e matemática no ensino fundamental. Diário Oficial da União, Brasília, DF, 11 de out, 2016.

CAVALIERE, Ana Maria Cavaliere. Notas sobre o conceito de educação integral. In: COELHO, Lígia Martha Coimbra da Costa. (Org.). Educação integral em tempo integral: estudos e experiências em processo. Rio de Janeiro: DP et Alii, 2009.

COELHO, Lígia Martha Coimbra da Costa. História(s) da educação integral. Brasília: Em Aberto, v.22, n. 80, p.83-96, abr. 2009.

FERNANDES, Claudia de Oliveira. Avaliação das aprendizagens: sua relação com o papel social da escola. São Paulo: Cortez, 2014.

FREITAS, Luiz Carlos de. A importância da avaliação: em defesa de uma responsabilização participativa. Em Aberto, Brasília, v. 29, n. 96 p. 127-139, maio/ago. 2016.

HOFFMAN, Jussara. Avaliação: mito e desafio: uma perspectiva construtivista. Porto Alegre: Mediação, 2005.

HORTA NETO, João Luiz.; JUNQUEIRA, Rogério Diniz. Sistema de Avaliação da Educação Básica (Saeb): 25 anos. Apresentação. Em aberto, v. 29, n. 96, p. 15-18, mai-ago 2016.

MAURÍCIO, Lúcia Velloso. Escritos, representações e pressupostos da escola pública de horário integral. Em Aberto, Brasília, v.22, n. 80, p.15-31, abr. 2009.

PARENTE, Claudia da Mota Darós. A construção dos tempos escolares. Educação em Revista. Belo Horizonte, v.26, n.02, p.135-156, 2010.

PARENTE, Claudia da Mota Darós. Nos tempos de escola: das discussões sobre antecipação e ampliação da escolarização ao direito à educação. Revista de Educação. São Paulo, v. 11, n. 12, 2008.

PARO, Vítor Henrique. Educação integral em tempo integral: uma concepção de educação para a modernidade. In: COELHO, Lígia Martha Coimbra da Costa. (Org.). Educação 
integral em tempo integral: estudos e experiências em processo. Rio de Janeiro: DP at Alii, 2009.

PESTANA, Maria Inês. Trajetória do Saeb: criação, amadurecimento e desafios. Em Aberto, v. 29, n. 96, $71-84$, maio/ago, 2016.

SIRINO, Marcio Bernardino. Trajetória da educação em tempo integral na rede municipal de ensino de Angra dos Reis (RJ): uma composição entre o universal e o focal? 2017. 196 f. Dissertação (Mestrado em Educação) - Programa de Pós-Graduação em Educação, Universidade Federal do Estado do Rio de Janeiro: Rio de Janeiro, 2017.

\section{Como referenciar este artigo}

SIRINO, Márcio Bernardino; MOTA, Patrícia Flávia. A avaliação da aprendizagem dos educandos que permanecem em tempo integral no município de Angra dos Reis/RJ por meio do Programa Novo Mais Educação: discussões preliminares sobre o papel da educação na construção do conhecimento. Revista on line de Política e Gestão Educacional, Araraquara, v.22, n.1, p. 381-394, jan./abr., 2018 ISSN: 1519-9029. DOI: 10.22633/rpge.v22.n.1.2018.10710

Submetido em: 28/11/2017

Aprovado em: 29/03/2018 